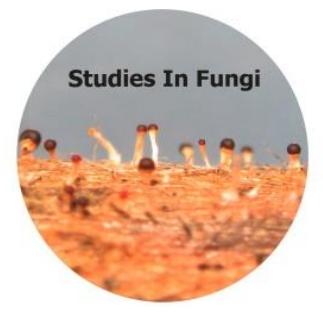

\title{
The soil fungi producing siderophores of Mt. Yangbew, Tawang, La Trinidad, Benguet
}

\author{
Hipol RM, Baldelomar JA, Bolinget KC and Solis AFF
}

Department of Biology, College of Science, University of the Philippines Baguio

Hipol RM, Baldelomar JA, Bolinget KC, Solis AFF 2019 - The soil fungi producing siderophores of Mt. Yangbew, Tawang, La Trinidad, Benguet. Studies in Fungi 4(1), 1-13, Doi 10.5943/sif/4/1/1

\begin{abstract}
Siderophores, being iron-chelators, have received much attention in environmental research, medicine, and biotechnology because of their high affinity and specificity to a wide range of metals. This study aimed to investigate siderophore production of culturable soil fungi from Mt. Yangbew, Tawang, La Trinidad, Benguet and to determine their chemical characteristics. Siderophore production was detected and quantified using Chrome Azurol Sulphonate assay while the siderophore characterization was through $\mathrm{FeCl}_{3}$, Csáky's and Arnow's tests. It was found that 11 out of 20 pure cultures, which showed positive CAS assay results, produce hydroxamates. ITS primers were used in PCR amplification for the molecular identification of the top-four siderophore-producers. Based on BLASTn analyses of their sequences, the isolates were found to be most homologous to species of Talaromyces, Byssochlamys, Paecilomyces, and Penicillium. The identified species were subjected to phylogenetic analysis using MEGA 7 to the show evolutionary history and relationship among the fungal species.
\end{abstract}

Key words - CAS assay - hydroxamates - iron chelators

\section{Introduction}

Iron $(\mathrm{Fe})$ as the fourth most abundant element in the terrestrial environment (Drechsel \& Winkelmann 1997) and is greatly needed by most microorganisms in order to perform several metabolic functions. It is greatly involved in the reduction of oxygen for ATP synthesis, in the reduction of DNA ribonucleotide precursors, and in the production of heme (Neilands 1995). It is also a cofactor for several enzymes like ribotide reductase, peroxidase, catalase, nitrogenase, ribotide reductase, and succinic dehydrogenase (Litwin \& Calderwood 1993).

This element exists in two readily inter-convertible oxidation states, Fe (II) and Fe (III). Such ability to convert between the two states allows iron to play an essential role in numerous electron transfer processes (Gray \& Winkler 1996).

Iron is prevalent in aerobic environments and exists as $\mathrm{Fe}_{2}\left(\mathrm{H}_{2} \mathrm{O}\right)_{6}{ }^{3+}$ but is not readily available for the uptake of microorganisms because its precipitates as oxyhydroxide polymers (Guerinot 1994) and, therefore, are insoluble in environmental conditions. Fe (III) is soluble in water at neutral $\mathrm{pH}$ at $10^{-18} \mathrm{M}$ (Raymond et al. 2003), a concentration far below the concentration required for growth which is about $10^{-7} \mathrm{M}$ in active microbes (Ishimaru \& Loper 1993). Iron, as a result, becomes a growth-limiting factor for many organisms.

In response to this condition, most microorganisms have evolved adaptive mechanisms that can solubilize iron (Neilands 1995). One such strategy is the production of siderophores, which are 
low molecular weight compounds (600 to 1500 Daltons) that chelate not only iron (Lankford 1973) but also other essential metals (Johnstone \& Nolan 2015) and heavy metals (Braud et al. 2009, Ruggiero et al. 1999).

Based on the chemical nature of their coordination sites, microbial siderophores may be classified as hydroxamates, catecholates, carboxylates, or mixed type (Renshaw et al. 2002). Bacteria secrete siderophores comprising a variety of functional groups (Hider 1984) while most fungi produce hydroxamate-type siderophores (Leong 1986).

In this study, soli fungi collected from Mt. Yangbew, Tawang, La Trinidad, Benguet was tested for their capacity to produce siderophores. The types of siderophores secreted were also investigated. The highest producers of siderophores were identified through molecular means. The identification of the siderophore-producing fungi will provide baseline data about the presence of native sources of siderophores for downstream studies relating to several applications that include agricultural and medical.

\section{Materials \& Methods}

\section{Collection of Soil Samples}

Composite soil sampling was carried out on 18 January 2017 in three locations at the summit of Mt. Yangbew in Tawang, La Trinidad, Benguet (Fig. 1). The coordinates and elevation of the sites were determined using a Garmin etrex® 10 GPS.

$>$ Location 1-coordinates: $16^{\circ} 27.222^{\prime} \mathrm{N}, 120^{\circ} 36.454^{\prime} \mathrm{E}$; elevation: 1652 masl

$>$ Location 2-coordinates: $16^{\circ} 27.260^{\prime} \mathrm{N}, 120^{\circ} 36.552^{\prime} \mathrm{E}$; elevation: 1657 masl

$>$ Location 3-coordinates: $16^{\circ} 27.271^{\prime} \mathrm{N}, 120^{\circ} 36.477^{\prime} \mathrm{E}$; elevation: 1647 masl

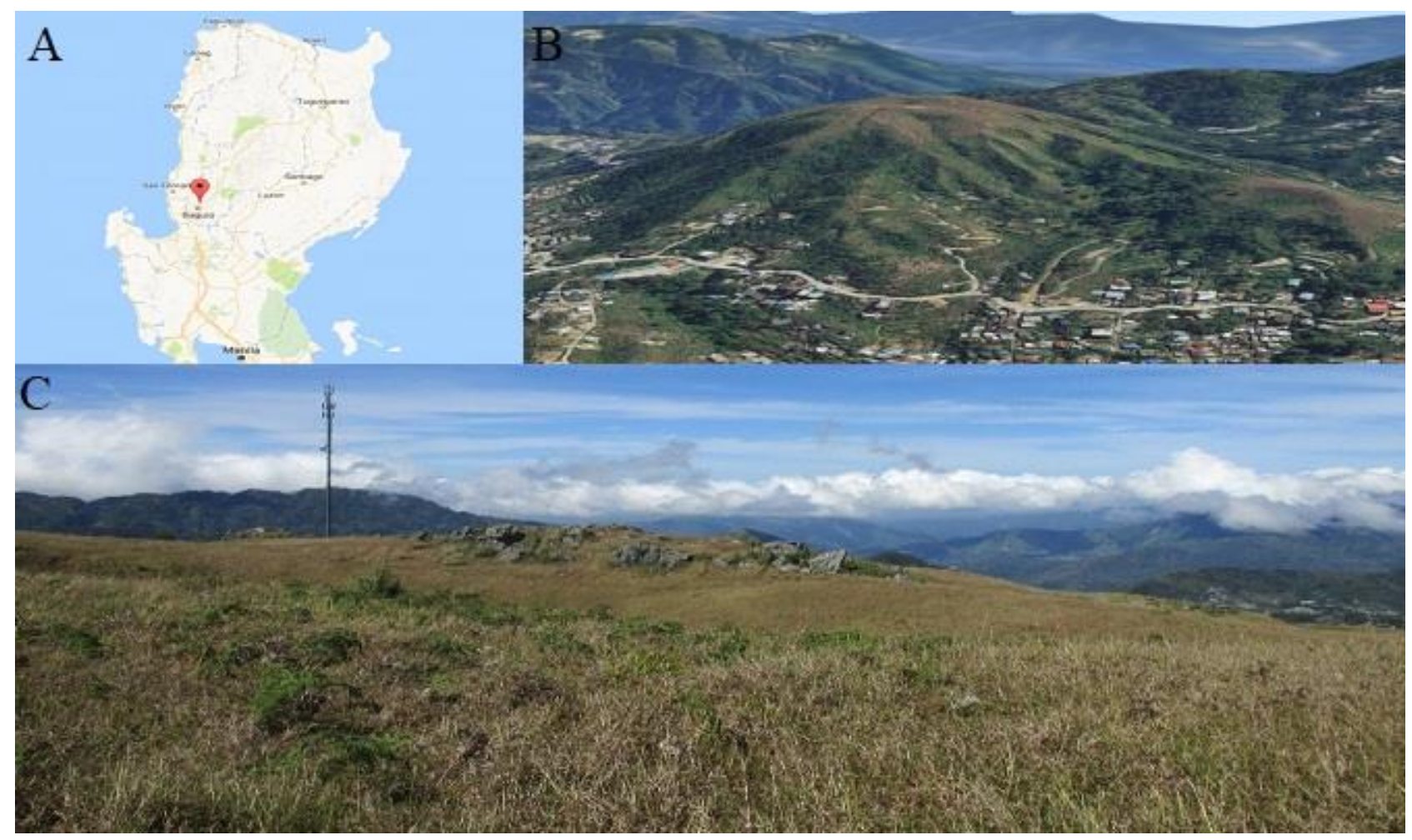

Fig. 1 - A Map of Luzon Island, Philippines showing the location of Mt. Yangbew relative to the capital Manila. Map data taken from Google Maps (C2017. B Satellite image of Mt. Yangbew in perspective view. Image taken from Google Earth (C2017. C Summit of Mt. Yangbew.

The soil samples were obtained using a soil corer and were placed separately in re-sealable bags. The moisture, temperature, and light intensity of each site were determined using a digital soil 
analyzer (Model KC300B, Shenzhen Technology Co., Ltd.). The pH of the collected soil sample was measured using a $\mathrm{pH}$ meter.

\section{Media Preparation}

In a clean $500 \mathrm{~mL}$ Erlenmeyer flask, $15.6 \mathrm{~g}$ of Potato Dextrose Agar (PDA) was added to 400 $\mathrm{mL}$ of distilled water. To inhibit most bacterial growth, $0.04 \mathrm{~g}$ of chloramphenicol was also added. The mixture was dissolved by thorough stirring and was microwaved oven to fully melt the agar. The flask was then covered with a cotton plug and the medium was autoclaved for sterilization. Five $\mathrm{mL}$ of the sterile melted medium was poured into sterilized Petri plates. Once the medium has solidified, the plates were sealed properly and inverted to prevent the accumulation of condensing moisture on the agar surface. The plates were stored in refrigerator for future use.

For the spread plating, rose Bengal chloramphenicol agar was used. In here, $0.04 \mathrm{~g}$ of rose Bengal (4,5,6,7-tetrachloro-2',4',5',7'-tetraiodofluorescein) was added to $400 \mathrm{~mL}$ PDAchloramphenicol mixture before sterilization. The presence of the stain suppresses the growth of bacteria and restricts the size and height of mold colonies (Banks et al. 1985), thereby aiding in the isolation of slow-growing fungi.

For PDA slants, test tubes covered with cotton plugs, each with $5 \mathrm{~mL}$ of prepared medium, were sterilized. After sterilization, the test tubes were laid across slanting boards, allowing the agar to solidify. The sterile media slants were refrigerated for future use.

\section{Serial Dilution and Spread Plating}

The stock soil suspension was prepared by adding 10 grams of the pooled soil (the mixture of the three collected soil samples) to $90 \mathrm{~mL}$ of distilled water in a clean beaker. The solution was thoroughly stirred to dispense and evenly distribute the microbial cells. A series of four consecutive dilutions (Wistreich 2003) was made $\left(10^{-1}, 10^{-2}, 10^{-3}, 10^{-4}\right)$ with 1:9 ratio $(1 \mathrm{~mL}$ from a lower dilution was added to $9 \mathrm{~mL}$ of distilled water in a separate clean test tube for the next higher dilution). The four tubes containing the diluted solutions were agitated using a vortex for uniform distribution of cells.

Dilutions $10^{-2}, 10^{-3}$, and $10^{-4}$ were plated into pre-poured PDA plates with Rose Bengal wherein six media plates were used for each dilution. Using a sterile L-rod, $0.1 \mathrm{~mL}$ or $100 \mu \mathrm{L}$ of each dilution was spread onto each plate. The plates were properly sealed and were incubated at $30{ }^{\circ} \mathrm{C}$ for 48 hours.

\section{Isolation, Purification, and Preparation of Stock Slant Cultures}

Morphologically distinct colonies from the inoculated PDA plates were picked and purified in freshly prepared media plates. Isolated discrete cultures were purified using a single-line streak plate inoculation for the first purification wherein the plates were incubated at $30^{\circ} \mathrm{C}$ for 48 hours. Grown cultures from these plates were subsequently transferred using an inoculating loop to new PDA plates without rose Bengal for a second purification, with another 2-day incubation. For stock cultures of the isolates, fungal growths on plates in second purification were inoculated into PDA slants using a single-line streak, starting at the bottom of the slanted agar surface and drawing the inoculating loop towards the topmost part of the agar. The inoculated agar slants were then incubated at $30^{\circ} \mathrm{C}$ for two days.

\section{Siderophore Production Media Preparation}

For siderophore production, Grimm-Allen medium (Grimm \& Allen 1954) was used. It contained $1 \mathrm{~g} \mathrm{~K}_{2} \mathrm{SO}_{4}, 3 \mathrm{~g}$ ammonium acetate, $3 \mathrm{~g} \mathrm{~K}_{2} \mathrm{HPO}_{4}, 1 \mathrm{~g}$ citric acid, and $20 \mathrm{~g}$ sucrose in $1 \mathrm{~L}$ of distilled water, and adjusted to $\mathrm{pH} 6.8$ with ammonia (Baakza et al. 2003). The medium was decontaminated of iron by adding 8-hydroxyquinoline dissolved in chloroform (Messenger \& Ratledge 1985) that, when shaken, formed ferrous or ferric hydroxyquinates. After separation, the chloroform layer was removed and the medium was washed repeatedly with chloroform to ensure 
complete removal of iron complexes and any residual 8-hydroxyquinoline, which could inhibit growth (Messenger \& Ratledge 1985).

A $50-\mathrm{mL}$ volume of the medium was dispensed into $500 \mathrm{~mL}$ conical flasks. Glassware used were soaked overnight in $6 \mathrm{~mol} / \mathrm{L} \mathrm{HCl}$ and rinsed with distilled water several times to remove traces of iron (Schwyn \& Neilands 1987). The growth medium was inoculated with an estimated concentration of $10^{8}$ fungal spores $/ \mathrm{mL}$ into flasks and incubated at $28 \pm 2{ }^{\circ} \mathrm{C}$. Filtrates of 15 -day old cultures were then subjected to chemical characterization assays.

\section{Chrome Azurol Sulphonate (CAS) Solution Preparation}

The production of siderophores by the isolated and purified microorganisms was screened using the CAS indicator solution (Schwyn \& Neilands 1987). The solution was prepared by first decanting $6 \mathrm{ml}$ of $10 \mathrm{mM}$ hexadecyltrimethylammonium bromide (HDTMA) solution in a 100-mL volumetric flask. Added to it was a mixture of $1.5 \mathrm{~mL}$ iron (III) chloride hexahydrate $\left(\mathrm{FeCl}_{3} \cdot 6 \mathrm{H}_{2} \mathrm{O}\right)$ and a $7.5 \mathrm{ml}$ of $2 \mathrm{mM}$ aqueous CAS dye solution were added in the flask. A buffer solution was then prepared by dissolving 4.307-g 1,4-piperazinediethanesulfonic acid (Pipes) in $30 \mathrm{~mL}$ distilled water, adjusting its $\mathrm{pH}$ to 5.6 using sodium hydroxide $(\mathrm{NaOH})$ before adding it to the solution. Lastly, to get a precise measurement of the solution, distilled water was poured slowly until the base of meniscus matched with the marked line in the volumetric flask (Yeole et al. 2001).

\section{Detection and Quantification of Siderophore Production}

Detection and quantification of siderophore production was based on Fekete et al. (1989) methodology, where $150 \mu \mathrm{L}$ of supernatant (15 day-old fungal cultures in Grim-Allen media) was added to $150 \mu \mathrm{L}$ CAS assay solution, obtaining a 1:1 ratio. A color change from blue to orange occurred which indicated the removal of iron from the dye (ternary) complex indicator (Barton \& Hemming 1993).

A filter-based multimode microplate reader (FLUOstar ${ }^{\circledR}$ Omega, BMG LABTECH) was used to detect the absorbance of the samples at $630 \mathrm{~nm}$. The CAS reagent was used as the blank solution. The amount of siderophore produced was computed in terms of their percentage siderophore units (\% SU) using the formula of Tailor \& Joshi (2012; Equation 1), where Ar is the absorbance of the CAS reagent and As is the absorbance of each sample, all at $630 \mathrm{~nm}$. This was done in triplicate and the standard error of the means was calculated.

$$
\% \text { Siderphore }=\frac{A r}{A s} \times 100
$$

(Equation 1)

The assay revealed the top four siderophore-producing fungi from the soil sample and was subjected to morphological and molecular identification.

\section{Detection of Hydroxamate Siderophores}

Presence of hydroxamate-type siderophores was determined using the quantitative Iron Perchlorate Test and the confirmatory colorimetric Csáky Assay.

\section{Iron Perchlorate Test}

To $1 \mathrm{~mL}$ of culture supernatant, $1-5 \mathrm{~mL}$ of freshly prepared aqueous $2 \% \mathrm{FeCl}_{3}$ solution was be added. The coordination of the metal ion with the siderophore yielded an orange color. The absorbance was measured between $200-600 \mathrm{~nm}$ and a peak at 420-450 nm indicated the presence of an orange-colored ferric hydroxamate (Atkin et al. 1970, Neilands 1981).

\section{Csáky Assay}

A 1-mL amount of culture supernatant was placed in test tube and was hydrolyzed with $1 \mathrm{~mL}$ of $6 \mathrm{~N} \mathrm{H}_{2} \mathrm{SO}_{4}$ in a boiling water bath for 6 hours. The solution was then buffered by adding $3 \mathrm{~mL}$ $35 \% \mathrm{NaOAc}$ solution and was followed by the addition of $0.5 \mathrm{~mL} \mathrm{I}_{2}$ solution $(1.3 \mathrm{~g}$ iodine per 100 
$\mathrm{mL}$ glacial acetic acid). After 3-5 minutes, excess $\mathrm{I}_{2}$ was destroyed with $1 \mathrm{~mL} \mathrm{Na}_{3} \mathrm{AsO}_{4}$ solution. One $\mathrm{mL} \alpha$-naphthylamine solution was added thereafter and color was allowed to develop. A wine red color indicated the presence of a hydroxamate type of siderophore (Adhikari et al. 2013, Ali \& Vidhale 2013, Csáky 1948).

\section{Detection of Catechol Siderophores}

The occurrence of catechol-type siderophores were detected using the quantitative Iron Perchlorate Test and the confirmatory colorimetric Arnow's Test.

\section{Iron Perchlorate Test}

Catecholate siderophores form a wine-colored complex with $\mathrm{a}_{\mathrm{mM}} \approx 5$ at $495 \mathrm{~nm}$ on addition of ferric chloride. To $1 \mathrm{~mL}$ of culture supernatant culture, $1 \mathrm{~mL}$ of $2 \% \mathrm{FeCl}_{3}$ was added. The formation of a wine-colored complex was monitored at $495 \mathrm{~nm}$ (Neilands 1981).

\section{Arnow's Test}

One $\mathrm{mL}$ culture supernatant was placed in a screw-capped tube and added with $1 \mathrm{~mL}$ nitritemolybdate reagent (containing $10 \mathrm{~g}$ each of $\mathrm{NaNO}_{2}$ and $\mathrm{Na}_{2} \mathrm{MoO}_{4} \cdot 2 \mathrm{H}_{2} \mathrm{O}$ in $50 \mathrm{~mL}$ water) and $1 \mathrm{ml}$ $0.5 \mathrm{~N} \mathrm{HCl}$ (a yellow-colored solution at this point). Finally, $1 \mathrm{~mL} 1 \mathrm{~N} \mathrm{NaOH}$ solution was added and red color indicates the presence of the catecholate type of siderophore (Jikare \& Chavan 2013, Arnow 1937).

\section{Morphological Analysis}

Pure cultures of the top four siderophore-producing fungi were inoculated on the center of the Petri plates $(9 \mathrm{~cm}$ diameter) containing PDA media with chloramphenicol $(200 \mu \mathrm{g} / \mathrm{ml})$ and incubated for 3 days. The macroscopic features of the four species were described including the height and width (in $\mathrm{cm}$ ), the color, and the growth characteristics such as surface, margin, elevation and form of the whole. These morphological characteristics were observed under a stereo zoom microscope (Model: SZM-B, OPTIKA Accessories).

\section{Molecular Identification and Phylogenetic Analysis}

The top four siderophore-producing isolates were sent to the sequencing laboratory of Macrogen, Inc. in Geumcheon-gu, Seoul, South Korea for precise genomic DNA extraction, PCR amplification, PCR purification, bidirectional sequencing, and BI report. The specific DNA sequence amplified was the ITS (internal transcribed spacer) region, with ITS1 (TCCGTAGGTGAACCTGCGG) and ITS4 (TCCTCCGCTTATTGATATGC) as the forward and reverse primers, respectively. Macrogen's sequencing analysis made use of a 3730xl DNA Analyzer (Applied Biosystems ${ }^{\mathrm{TM}}$ ).

Information on the resultant primary biological sequences were then compared to deposited nucleotide DNA sequences in public databases using the National Center for Biotechnology Information's Basic Local Alignment Search Tool (BLAST), specifically the nucleotide-nucleotide BLAST (blastn), to determine the most similar DNA sequences from the database to the fungal species positive for siderophore production (Altschul et al. 1990). The ITS sequences were placed within tentative taxa by determining the sequence from the GenBank database it is most homologous to.

Multiple sequence alignments of ITS sequences were performed using ClustalW. Phylogenetic analysis was conducted through MEGA7: Molecular Evolutionary Genetics Analysis version 7.0 for bigger datasets by Maximum Likelihood method and the evolutionary history was inferred using Kimura 2-parameter model (Kimura 1980). A discrete Gamma distribution was used to model evolutionary rate differences among sites $(5$ categories $(+\mathrm{G}$, parameter $=0.4699)$ ). Statistical significance of the tree branches was evaluated by bootstrap analysis based on 1000 bootstrap replicates. 


\section{Results}

Twenty isolates of distinct fungal colonies were cultured from the soil sample of Mt. Yangbew in Tawang, La Trinidad, Benguet. Purified cultures were designated as isolate BBS-001 to isolate BBS-020. Siderophore production was determined and those that showed a positive result were subjected to a comprehensive screening.

\section{Detection of Siderophore Production}

Out of 20 isolates, only 10 showed a positive result in the CAS assay, the universal test for the detection of siderophores (see Fig. 2). These isolates, BBS-001, BBS-003, BBS-004, BBS-005, BBS-006, BBS-007, BBS-008, BBS-0015, and BBS-0019, were subjected to several assays that determined the type of siderophore they produced.

Furthermore, Fig. 2 show that six isolates exhibited more than $90 \%$ SU, the highest being BBS-008 with $97.91 \%$ SU, while the four others were below $70 \%$ SU, with the lowest at $47.38 \%$ SU being BBS-004. These four isolates with the highest siderophore units produced were subjected for molecular identification. Following the top producer BBS-008 was BBS-006 with 97.73\% SU, BBS-019 ranked third with $92.76 \%$ SU, and BBS-005 ranked fourth with $92.32 \%$ SU produced.

\section{Chemical Characterization of Siderophores}

Qualitative tests were performed in conjunction with the quantitative UV spectrophotometric methods to evaluate the production of siderophores by the isolated rhizosphere fungi. Nine out of the 10 siderophores tested positive in the detection for hydroxamate-type (Table 1). They recorded a maximum absorbance between $420 \mathrm{~nm}-450 \mathrm{~nm}$ in the $\mathrm{FeCl}_{3}$ test and between $420 \mathrm{~nm}-495 \mathrm{~nm}$ in the Csáky assay. Other authors have considered a wine-red color development in the latter as indicative for hydroxamate production, even with no spectrophotometric analysis.

Only BBS-004 and BBS-005 gave positive results in both the tests that detected Nhydroxylated amine bonds with peaks at $432 \mathrm{~nm}$ and $440 \mathrm{~nm}$, respectively, in the $\mathrm{FeCl}_{3}$ test. Isolate BBS-001 exhibited maximum absorbance at $424 \mathrm{~nm}$, BBS-007 at $438 \mathrm{~nm}$, and BBS-009 had multiple peaks ( $424 \mathrm{~nm}, 428 \mathrm{~nm}, 438 \mathrm{~nm}$, and $448 \mathrm{~nm}$ ) within the desired range of absorbance. These three, however, failed to show a positive result in the Csáky assay. Isolate BBS-003 developed a wine-red color in the Csáky assay and this was supported by having multiple maximum absorbance at $420 \mathrm{~nm}, 423 \mathrm{~nm}, 432 \mathrm{~nm}$, and $440 \mathrm{~nm}$. A similar occurrence was also observed for BBS-015 where four absorbance peaks (422 nm, $432 \mathrm{~nm}, 446 \mathrm{~nm}$, and $450 \mathrm{~nm}$ ) were noted. Isolates BBS-006, BBS-008, and BBS-019 all developed a wine-red color. BBS-002 failed to show positive results in tests for both hydroxamate and catecholate tests.

Table 1 Detection of the chemical nature of siderophores

\begin{tabular}{lcccc}
\hline \multirow{2}{*}{ Isolate } & Hydroxamate & \multicolumn{3}{c}{ Catecholate } \\
\cline { 2 - 5 } & $\begin{array}{l}\mathrm{FeCl}_{3} \text { Test } \\
(420 \mathrm{~nm}-450 \mathrm{~nm})\end{array}$ & $\begin{array}{c}\text { Csáky Assay } \\
(420 \mathrm{~nm}-495 \mathrm{~nm})\end{array}$ & $\begin{array}{l}\mathrm{FeCl}_{3} \text { Test } \\
(420 \mathrm{~nm}-450 \mathrm{~nm})\end{array}$ & $\begin{array}{c}\text { Arnow's Test } \\
(515 \mathrm{~nm})\end{array}$ \\
\hline BBS-001 & - & - & - & - \\
BBS-003 & - & + & - & - \\
BBS-004 & + & + & - & - \\
BBS-005 & + & + & - & - \\
BBS-006 & - & + & - & - \\
BBS-007 & + & - & - & - \\
BBS-008 & - & + & - & - \\
BBS-009 & + & - & - & - \\
BBS-015 & - & + & - & - \\
BBS-019 & - & + & - & \\
\hline$* *(+)-$ positive & & & &
\end{tabular}




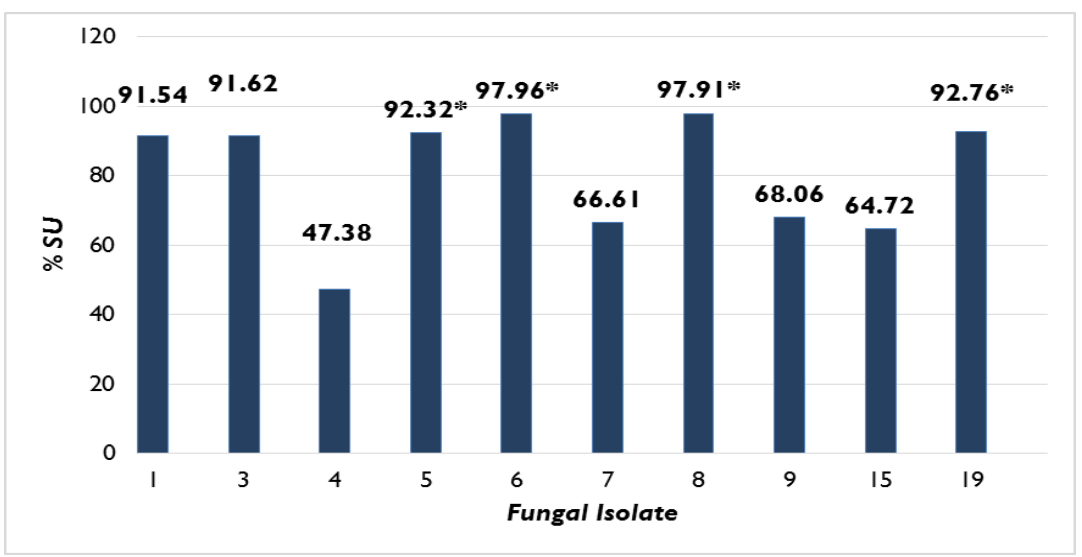

Fig. 2 - Quantification of siderophore production by fungal isolates (in \% siderophore units, SU). Asterisks after the data labels denote that the isolate belong to the top four producers.

\section{Morphology and Identification of Siderophore-Producing Fungal Isolates}

The fungal isolates were subjected to colony morphology for preliminary identification. There were noticeable differences in the morphological characteristics of the colonies of the isolates (Table 2), specifically on their appearance in PDA medium, size (in mm), color, reverse color, surface of mycelial texture, margin, elevation, and form. Conidial area of BBS-008 were yellow orange, while the other three all had white margins with either brown or bluish centers. All isolates exhibited a circular colony form except BBS-005 which was irregularly shaped. The colonies of BBS-008 and BBS-005 were both wrinkled while those of BBS-006 and BBS-019 were dry and powdery.

Along with colony morphology, the isolates were subjected to molecular characterization. DNA sequences showing $\geq 98 \%$ similarity was considered to belong to the same species (Arnold \& Lutzoni 2007) while sequences showing $\geq 95 \%$ similarity were considered to belong to the same genus. Sequences that showed $<95 \%$ similarity were considered unidentified taxon. Table 3 shows the nearest matches for the two ITS sequences to deposited strains in the database.

Isolate BBS-008, which has the maximum siderophore production, was most homologous with a strain of Talaromyces tardifaciens, with maximum identity at $96 \%$. This was also the percentage for the nearest match of BBS-006, which is Byssochlamys nivea. Putative taxonomic affinities for isolates BBS-019 and BBS-005 were Paecilomyces formosus (96\%) and Penicillium citrinum $(99 \%)$, respectively.

The phylogenetic affinities of the fungal isolates (Fig. 3) were determined through phylogenetic analysis using MEGA7. Evolutionary history was inferred using the Maximum Likelihood method based on the Kimura 2-parameter model (Kimura 1980) with a discrete Gamma distribution to model evolutionary rate differences among sites $[5$ categories $(+\mathrm{G}$, parameter $=$ 0.4699)]. The consensus tree was constructed from fifteen aligned nucleotide sequences-11 reference sequences obtained through BLASTn search and the four isolates' sequences - with 1000 bootstrap replications. The reference sequences selected were those that had the highest sequence percentage homology to the queries. The siderophore-producing zygomycete fungi Cunninghamella elegans served as the outgroup.

\section{Discussion}

\section{Detection and characterization of siderophores}

The screening of 20 fungal isolates cultured from the soil of Mt. Yangbew, Tawang, La Trinidad, Benguet by the CAS assay and $\mathrm{FeCl}_{3}$ test demonstrated the widespread occurrence of siderophores in fungi in iron uptake. The high levels of siderophores produced, especially of the top four isolates, were indicative that the fungal species were highly adapted to iron-unavailable conditions. 
Among the isolates successfully grown in the GA medium, six out of 10 recorded $>90 \%$ siderophore production while four were below $70 \%$. It is only logical that there are differences in the quantity of siderophores produced by different microorganisms. Reigh \& O'Cannell (1988), Roy et al. (1994) claimed reports of strain-to-strain variation in siderophore production.

All the siderophores secreted by the fungal isolates were detected as hydroxamates and no catecholate-type was detected, validating reports of their usual occurrence only in bacteria (Dave \& Dube 2000). Catecholate siderophores have been reported in fungi but their occurrence is rarer. A marine fungus, Penicillium bilaii, was found to produce pistillarin, a rare catechol siderophore, when grown under relatively high-iron conditions (Capon et al. 2007).

Table 2 Colony morphology of top four siderophore-producing fungi isolated from the rhizosphere of Mt. Yangbew

\begin{tabular}{|c|c|c|c|c|c|c|c|c|}
\hline Fungal Isolate & $\begin{array}{l}\text { Colony } \\
\text { Appearance }\end{array}$ & Size (mm) & Color & Reverse Color & Surface & Margin & Elevation & Form \\
\hline BBS-008 & & $18 \times 16$ & Yellow orange & Orange & Wrinkled & Entire & Umbonate & Circular \\
\hline BBS-006 & & $44 \times 44$ & $\begin{array}{l}\text { Brown center, } \\
\text { white margin }\end{array}$ & $\begin{array}{l}\text { Yellow with } \\
\text { white margin }\end{array}$ & Dry, powdery & Entire & $\begin{array}{l}\text { Raised, } \\
\text { spreading edge }\end{array}$ & Circular \\
\hline BBS-019 & & $40 \times 40$ & $\begin{array}{l}\text { Brown center, } \\
\text { white margin }\end{array}$ & $\begin{array}{l}\text { Yellow with } \\
\text { white margin }\end{array}$ & Dry, powdery & Entire & $\begin{array}{l}\text { Raised, } \\
\text { spreading edge }\end{array}$ & Circular \\
\hline BBS-005 & & $17 \times 15$ & $\begin{array}{l}\text { Blue green with } \\
\text { white margin }\end{array}$ & White & Wrinkled & Lobate & $\begin{array}{l}\text { Wrinkled } \\
\text { convex }\end{array}$ & Irregular \\
\hline
\end{tabular}


Table 3 Putative taxonomic affinities of sequenced types inferred from BLASTn searches of ITS sequences

\begin{tabular}{|c|c|c|c|c|c|}
\hline Isolate & $\begin{array}{l}\text { ITS1 Nearest } \\
\text { Match }\end{array}$ & $\begin{array}{l}\text { Max Identity } \\
(\%)\end{array}$ & $\begin{array}{l}\text { ITS4 Nearest } \\
\text { Match }\end{array}$ & $\begin{array}{l}\text { Max Identity } \\
(\%)\end{array}$ & Identity \\
\hline BBS-008 & $\begin{array}{l}\text { Talaromyces } \\
\text { loliensis CBS } \\
643.80 \\
(\text { KF984888.1) }\end{array}$ & $94 \%$ & $\begin{array}{l}\text { Talaromyces } \\
\text { tardifaciens } \text { CBS } \\
250.94 \\
(\text { KF984874.1) }\end{array}$ & $96 \%$ & $\begin{array}{l}\text { Talaromyces } \\
\mathrm{sp}\end{array}$ \\
\hline BBS-006 & $\begin{array}{l}\text { Byssochlamys } \\
\text { fulva CBS } 146.48 \\
(\mathrm{NR} 103603.1)\end{array}$ & $92 \%$ & $\begin{array}{l}\text { Byssochlamys } \\
\text { nivea MUCL } \\
39714 \\
\text { (DQ464362.1) }\end{array}$ & $96 \%$ & $\begin{array}{l}\text { Byssochlamys } \\
\mathrm{sp}\end{array}$ \\
\hline BBS-019 & $\begin{array}{l}\text { Paecilomyces } \\
\text { formosus CBS } \\
990.73 \mathrm{~B} \\
(\mathrm{FJ} 389929.1)\end{array}$ & $96 \%$ & $\begin{array}{l}\text { Paecilomyces } \\
\text { formosus CBS } \\
990.73 \mathrm{~B} \\
(\mathrm{FJ} 389929.1)\end{array}$ & $96 \%$ & $\begin{array}{l}\text { Paecilomyces } \\
\text { sp }\end{array}$ \\
\hline BBS-005 & $\begin{array}{l}\text { Penicillium } \\
\text { citrinum NRRL } \\
1841 \\
(\text { NR_121224.1) }\end{array}$ & $96 \%$ & $\begin{array}{l}\text { Penicillium } \\
\text { citrinum NRRL } \\
1841 \\
(\text { NR_121224.1) }\end{array}$ & $99 \%$ & $\begin{array}{l}\text { Penicillium } \\
\text { citrinum }\end{array}$ \\
\hline
\end{tabular}

The production of hydroxamate siderophores has been reported in numerous fungi starting with the first report of siderophore from Ustilago sphaerogena (Winkelmann 1992). In terms of possible applications, hydroxamate siderophores are better than catecholates for agriculture because they are comparatively stable, have high iron-chelating abilities (Kloepper et al. 1980), and impart suppressiveness to the soil, which is important for preventing the growth of phytopathogens (Mazzola 2002).

\section{Molecular Identification of Siderophore-Producing Fungi}

The internal transcribed spacer (ITS) region, which contains the 5.8S gene and is located between the $18 \mathrm{~S}$ and $26 \mathrm{~S}$ rRNA genes, has the highest probability of successful identification for the broadest range of fungi, with the most clearly defined barcode gap between inter- and intraspecific variation (Schoch et al. 2012). Deducing the relation of the isolate sequences to reference sequences (Table 3) was based on Arnold \& Lutzoni (2007) suggested threshold cut off for genus and species acceptance where a $95 \%$ sequence similarity for the ITS region is considered as a conservative species boundary.

The occurrence of the four fungal genera in the soil is expected as they have been isolated from soils beforeTalaromyces is a genus of about 25 species, also mostly soil inhabiting and is typical in warmer climates (Pitt \& Hocking 1997). The Penicillium genus is diverse in terms of numbers of species and range of habitats.

Penicillium citrinum has been reported to secrete iron-chelators (Baakza et al. (2003). Five new coprogen-type hydroxamate siderophores were discovered from an Australian mud dauber wasp-associated unspecified species of Talaromyces (CMB-W045), along with three others that were first detected in other fungal isolates (Kalansuriya et al. 2017). Paecilomyces variotii was found to produce both hydroxamate and carboxylate siderophores, suggesting that carboxylates could also be present outside Mucorales (Vala et al. 2000). Other species of Paecilomyces were also reported to produce hydroxamate siderophores- $P$. lilacinus and Paecilomyces sp. AB7 (Baakza et al. 2003). For Penicillium, P. resticulosum (Konetschny-Rapp et al. 1988), $P$. funiculosum, P. oxalicum, and P. fellutanum (Baakza et al. 2003) all tested positive for hydroxamate-type siderophores. It is only the genus Byssochlamys that has not been reported to produce siderophores. 


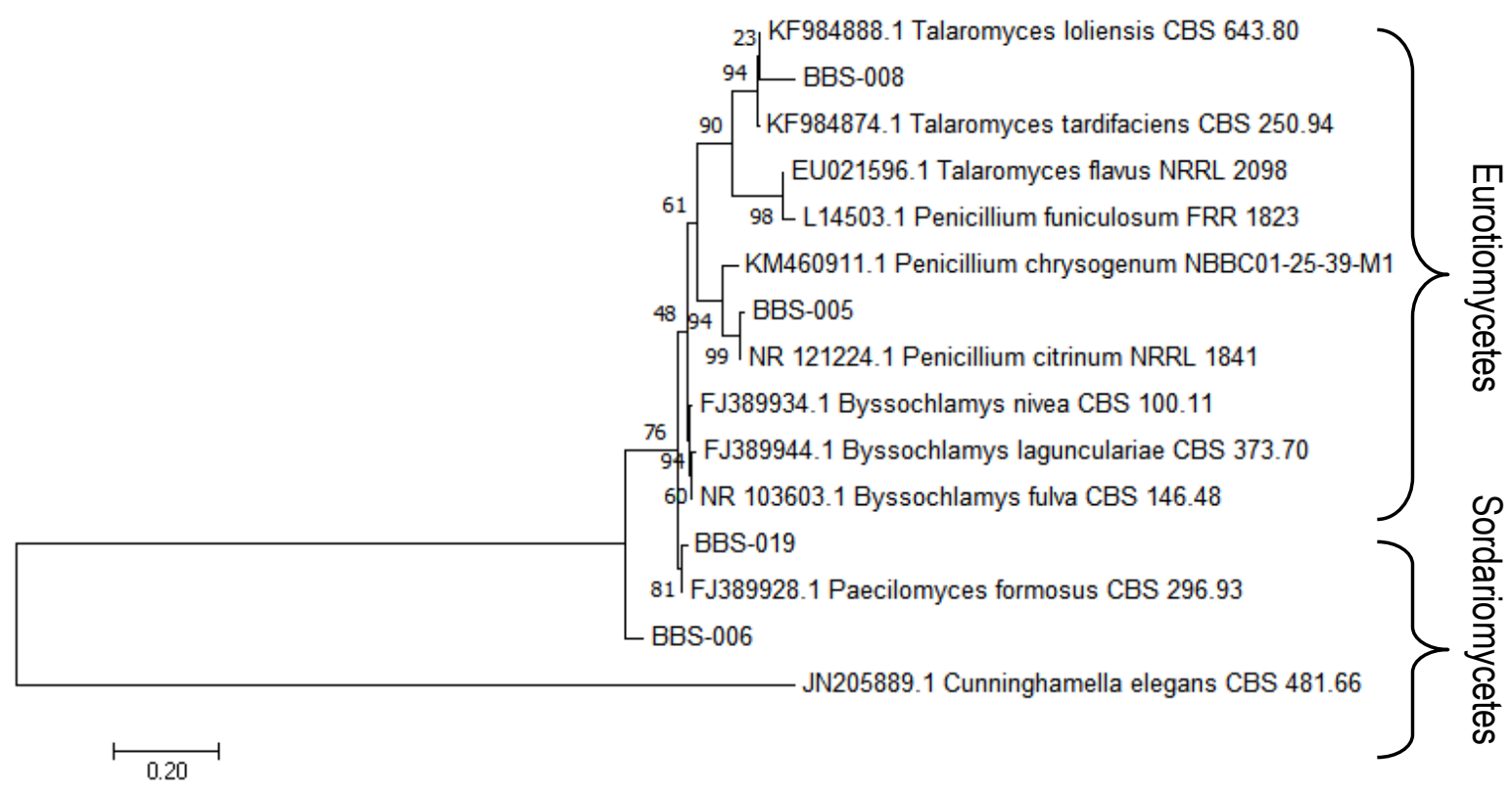

Fig. 3 - Phylogenetic tree by Maximum Likelihood method showing the relationship among fungal ITS sequences from the soil microbiota of Mt. Yangbew in La Trinidad, Benguet with reference sequences obtained through BLAST. The evolutionary history was inferred by using the Maximum Likelihood method based on the Kimura 2-parameter model (Kimura 1980). Initial tree(s) for the heuristic search were obtained automatically by applying Neighbor-Join and BioNJ algorithms to a matrix of pairwise distances estimated using the Maximum Composite Likelihood (MCL) approach, and then selecting the topology with superior log likelihood value. A discrete Gamma distribution was used to model evolutionary rate differences among sites ( 5 categories $(+G$, parameter $=0.3816))$. Bootstrap values $(1000$ replicates $)$ are shown at the nodes. The tree is drawn to scale, with branch lengths measured in the number of substitutions per site. There was a total of 321 positions in the final dataset. Evolutionary analyses were conducted in MEGA7 (Kumar et al. 2016).

Phylogenetic analyses showed that the sequenced soil isolates belonged to two subclades under the Phylum Ascomycota, which is the largest within the kingdom Fungi. Isolates BBS-006 and BBS-019 fall under Sordariomycetes while BBS-008 and BBS-005 belong to Eurotiomycetes.

BBS-005 was found to be closely related to Penicillium citrinum with $99 \%$ similarity (Table 3) and supported by a high bootstrap value of 99 (Fig. 3). Its affinity to the siderophore producer $P$. chrysogenum (not reference sequence) was also well-supported at a 94-bootstrap value, suggesting that the isolate is indeed Penicillium citrinum. The phylogenetic placement of BBS-008 clustering with T. tardifaciens (96\% similarity to ITS4 according to BLASTn) was also highly-supported (bootstrap value is 94). Its affiliation, however, to the nearest match for its ITS1 sequence ( $T$. loliensis) was not supported at $23 \%$ bootstrap value.

The consensus tree shows that the three reference Byssochlamys species and BBS-019whose identity as $P$. formosus was well-supported by the $86 \%$ bootstrap value-was found to branch out from BBS-006, which was most homologous to B. nivea $(96 \%$ similarity to its ITS sequence). The nearest phylogenetic neighbor of the BBS-006 was Paecilomyces, indicating that it may be more related to it than its reference species. Such divergence may be explained by Stolk \& Samson (1971) who revised the genus Byssochlamys with the discovery of it having Paecilomyces anamorphs, which, in contrast to the former's sexual state, are asexual.

\section{Conclusion}

This study demonstrated strain-to-strain differences in the production of siderophores. The seven fungal isolates having more than $90 \%$ SU imply that they are well-adapted to an iron-limited 
conditions than those below $90 \%$, confirming that siderophore-mediated iron uptake is important to rhizosphere fungi in Mt. Yangbew, Tawang, La Trinidad, Benguet. Also, fungi from the collection site predominantly produce hydroxamate siderophores.

Siderophores of the identified fungal isolates have been reported, except for Byssochlamys. This study is the first to present evidence of production of hydroxamate siderophores in this genus.

For future biotechnological applications, the top four identified siderophore-producing fungi from Mt. Yangbew, Tawang, La Trinidad, Benguet may be considered. Possible applications include bioremediation of heavy metal pollution, biological control of microbial plant pathogens, as well as biomedical studies. The elucidation of the chemical structure of the siderophores is also a promising endeavor, especially which of BBS-06 identified as Byssochlamys sp.

\section{Acknowledgements}

The authors would like to acknowledge the support of the Department of Biology, College of Science, University of the Philippines Baguio for the conduct of this study.

\section{References}

Adhikari A, Sarker K, De Roy M, Bhattacharya I et al. 2013 - Siderophore mediated antagonism of fluorescent Pseudomonads against soil borne plant pathogenic fungi in West Bengal, India. African Journal of Microbiology Research, 7(39), 4689-4700.

Ali SS, Vidhale NN. 2013 - Bacterial siderophore and their application: A review. International Journal of Current Microbiology and Applied Sciences, 2 (12): 303-312.

Altschul S, Gish W, Miller W, Myers EW, Lipman DJ. 1990 - Basic local alignment search tool. Journal of Molecular Biology, 215(3), 403-410.

Arnold AE, Lutzoni F. 2007 - Diversity and host range of foliar fungal endophytes: Are tropical leaves biodiversity hotspots? Ecology, 88: 541-549.

Arnow LE. 1937 - Colorimetric determination of the components of 3,4-dihydroxyphenylalanine tyrosine mixtures. Journal of Biological Chemistry, 118, 531.

Atkin CL, Neilands JB, Phaff H. 1970 - Rhodotorulic acid from species of Rhodospirillum, Rhodotorula, Sporidiobolus and Sporobolomyces and a New Alanine - Containing Ferrichrome from Cryptococcus melibiosum. Journal of Bacteriology, 103, 722-733.

Baakza A, Vala AK, Dave BP, Dube HC. 2003 - A comparative study of siderophore production by fungi from marine and terrestrial habitat. Journal of Experimental Marine Biology and Ecology, 311, 1-9.

Banks JG, Board RG, Carter J, Dodge AD. 1985 - The cytotoxic and photodynamic inactivation of microorganisms by Rose Bengal. Journal of Applied Bacteriology, 58: 391-400.

Barton LL, Hemming BC. 1993 - Iron Chelation in Plants and Soil Microorganisms. San Diego, Calilfornia: Academic Press, Inc.

Braud A, Jézéquel K, Bazot S, Lebeau T. 2009 - Enhanced phytoextraction of an agricultural Cr-, $\mathrm{Hg}$ and $\mathrm{Pb}$-contaminated soil by bioaugmentation with siderophore producing bacteria. Chemosphere 74, 280-6.

Capon RJ, Stewart M, Ratnayake R, Lacey E, Gill JH. 2007 - Citromycetins and bilains A-C: new aromatic polyketides and diketopiperazines from Australian marine-derived and terrestrial Penicillium spp. Journal of Natural Products, 70 (11), 1746-52.

Csáky TZ. 1948 - On the estimation of bound hydroxylamine in biological materials. Acta Chemica Scandinavica, 2: 450-454.

Dave BP, Dube HC. 2000 - Chemical characterization of fungal siderophores. Indian Journal of Experimental Biology, 38, 56-62.

Drechsel H, Winkelmann G. 1997 - Iron chelation and siderophores. In G. Winkelmann and C. J. Carrano (Eds.), Transition Metals in Microbial Metabolism. Netherlands: Harwood Academic Publishers. pp. 1-49 
Fekete FA, Chandhoke V, Jellison J. 1989 - Iron-binding compounds produced by wood decaying basidiomycetes. Applied and Environmental Microbiology. 55, 2720-2722.

Gray HB, Winkler JR. 1996 - Electron transfer in proteins. Annual Review in Biochemistry. 65, 537-561. doi: 10.1146/annurev.bi.65.070196.002541.

Grimm PW, Allen PJ. 1954 - Promotions by microorganisms in formation of cytochromes in Ustilago sphaerogena. Plant Physiology, 29, 369-377.

Guerinot M, Yi Y. 1994 - Iron: Nutritious, Noxious, and Not Readily Available. Plant Physiology, 104 (3): 815-820.

Hider RC. 1984 - Siderophore mediated absorption of iron. Structure and Bonding, 58: 26-87.

Ishimaru CA, Loper JE. 1993 - Biochemical and genetic analysis of siderophores produced by plant-associated Pseudomonas and Erwinia species. In L. B. Barton and B. C. Hemming (eds.), Iron Chelation in Plants and Soil Microorganisms. Cambridge, MA: Academic Press, Inc.

Jikare A, Chavan M. 2013 - Screening of siderophore producing bacteria from groundnut field of solapur. International Journal of Universal Pharmacy and life, 3(6): 21-27.

Johnstone TC, Nolan EM. 2015 - Beyond Iron: Non-Classical Biological Functions of Bacterial Siderophores. Dalton Transactions, 44(14): 6320-6339. doi. 10.1039/c4dt03559c.

Kalansuriya P, Quezada M, Esposito G, Capon RJ. 2017 - Talarazines A-E: Noncytotoxic Iron(III) Chelators from an Australian Mud Dauber Wasp-Associated Fungus, Talaromyces sp. (CMBW045). Journal of Natural Products. 80, 609-615.

Kimura M. 1980 - A simple method for estimating evolutionary rate of base substitutions through comparative studies of nucleotide sequences. Journal of Molecular Evolution, 16:111-120.

Kloepper JW, Leong J, Teintze M, Shroth MN. 1980 - Enhanced plant growth by siderophores produced by plant growth promoting rhizobacteria. Nature, 286: 885-886.

Konetschny-Rapp S, Huschka HG, Winkelmanne G, Jung G. 1988 - High-performance liquid chromatography of siderophores from fungi. Biology of Metals, 1: 9 . doi:10.1007/BF01128012.

Kumar S, Stecher G, Tamura K. 2016 - MEGA7: molecular evolutionary genetics analysis version 7.0 for bigger datasets. Molecular biology and evolution, 33(7), 1870-1874.

Lankford CE. 1973 - Bacterial assimilation of iron. Critical Reviews in Microbiology, 2: 273-331.

Leong J. 1986 - Siderophores: their biochemistry and possible role in the biocontrol of plant pathogens. Annual Review of Phytopathology, 24: 187-209.

Litwin CM, Calderwood SB. 1993 - Role of iron in the regulation of virulence genes. Clinical Microbiology Reviews, 6: 137-149.

Mazzola M. 2002 - Mechanism of natural soil suppressiveness to soil borne diseases. Anton van Leeuwenhook, 81: 557-564.

Messenger AJM, Ratledge C. 1985 - Siderophores. In: M. Moo-Young (Ed.), Comprehensive Biotechnology (pp. 275-295). New York, NY: Pergamon Press.

Neilands JB. 1981 - Microbial iron compounds. Annual Review of Biochemistry, 50: 715-731.

Neilands JB. 1995 - Siderophores: Structure and Function of Microbial Iron Transport Compounds. The Journal of Biological Chemistry, 270: 26723-26726. doi: 10.1074/jbc.270.45.26723.

Pitt JJ, Hocking AD. 2009 - Penicillium and related genera. In Pitt, J. J. and Hocking, A. D. (eds.), Fungi and Spoilage. New York, NY: Springer Science+Business Media, LLC. pp. 169-273. doi: 10.1007/978-0-387-92207-2_7.

Raymond KN, Dertz EA, Kim SS. 2003 - Enterobactin: An archetype for microbial iron transport. Proceedings of the National Academy of Sciences of the United States of America, 100 (7): 3584-3588. doi: 10.1073/pnas.0630018100.

Reigh G, O'Connell M. 1988 - Siderophore production is strain specific in Rhizobium. In: Bothe, H., DeBruijin, F. J., Newto, and W. E. (eds.), Nitrogen Fixation: Hundred Years After. New York, NY: Gustav Fischer Verlag. pp. 826-839. 
Renshaw JC, Robson GD, Trinci AP, Wiebe MG et al. 2002. Fungal siderophores: structures, functions and applications. Mycological Research, 106 (10): 1123-1142. doi: 10.1017/S0953756202006548.

Roy N, Bhatacharya P, Chakrabartty PK. 1994 - Iron acquisition during growth in an iron-deficient medium by Rhizobium sp. isolated from Cicer arietium. Microbiology, 140: 2811-2820.

Ruggiero CE, Neu MP, Vanderberg LA. 1999 - Plutonium and uranium interactions with siderophores of aerobic soil microbes. Journal of Inorganic Biochemistry, 74: 282.

Schoch CL, Seifert KA, Huhndorf S, Robert V et al. 2012 - Nuclear ribosomal internal transcribed spacer (ITS) region as a universal DNA barcode marker for Fungi. Proceedings of the National Academy of Sciences of the United States of America, 109 (16): 6241-6246.

Schwyn B, Neilands JB. 1987 - Universal chemical assay for the detection and determination of siderophores. Analytical Biochemistry, 160: 47-56.

Stolk AC, Samson RA. 1971 - Studies on Talaromyces and related genera. 1. Hamigera gen. nov. and Byssochlamys. Persoonia, 6: 341-357.

Tailor AJ, Joshi BH. 2012 - Characterization and optimization of siderophore production from Pseudomonas fluorescens strain isolated from sugarcane rhizosphere. Journal of Environmental Research and Development, 6 (3A): 688-694.

Vala AK, Vaidya SY, Dube HC. 2000 - Siderophore production by facultative marine fungi. Indian Journal of Marine Sciences, 29: 339-340.

Winkelmann G. 1992 - Structures and functions of fungal siderophores containing hydroxamate and complexone type iron binding ligands. Mycological Research, 96: 529-534.

Wistreich G. 2003 - Microbiology Laboratory: Fundamentals and Applications (2 ${ }^{\text {nd }}$ ed.). Upper Saddle River, NJ: Pearson Education, Inc.

Yeole RD, Dave BP, Dube HC. 2001 - Siderophore production by fluorescent pseudomonads colonizing roots of certain crop plants. Indian Journal of Experimental Biology, 39: 464-468. 